Vietnam Journal of Mechanics, NCST of Vietnam Vol. 23, 2001, No 3 (183 - 192)

\title{
TAYLOR BUBBLE VELOCITY MEASUREMENTS IN TWO-PHASE AIR/WATER VERTICAL FLOW
}

\author{
T. Bui DinH \\ Institute of Mechanics
}

\begin{abstract}
An experimental technique for the measurement of the instantaneous rising velocity of a single Taylor bubble in two-phase air/water vertical flow is proposed. Mear surements are based on the multiple successive digital images and binary image processing techniques. The instantaneous velocity of a bubble is expressed as a function separation distance between the two consecutive bubble nose tips (or the position of the center of the bubble). This experimental technique allows studying and measuring with high accuracy both types of flow: full developed and developing slug flows. The major part of this work (experimental set-up, images digitization) is carried out at Kwangju Institute of Science \& Technology (KJIST) in Korea.
\end{abstract}

\section{Introduction}

Gas-liquid slug flow is a flow pattern encountered when the two phases flow simultaneously upward in vertical tube. This flow pattern is characterized by large bubbles, which will be referred to as G. I. Taylor bubbles. This pattern is frequently observed in a variety of industrial situations including geothermal, oil and gas wells and pipelines, process vaporizer and the riser section of boiling nuclear reactors, etc.

The motion of Taylor bubbles in liquid flow is a basic phenomenon in slug flow. In general, slug flow is undesirable because of violent pressure fluctuations and hence it is important to investigate the behaviour of Taylor bubbles.

The rising velocity of a single Taylor bubble in stagnant and moving liquid in a vertical pipe has been studied by numerous authors, both theoretically as Dumitrescu (1943), Davies and Taylor (1949), Moissis and Griffith (1962), Barnea and Brauner (1985), Barnea and Taitel (1993), Mao and Dukler (1990), and experimentally by Griffith and Wallis (1961), White and Beardmore (1962), Nicklin D.J (1962), Nicklin et al. (1962), Mao and Dukler (1991), and recently Hills and Chety (1998), etc.

Moreover, most of the data are related to the flow around the nose of the bubble and the Taylor bubble velocity obtained is based on the propagation velocity of the bubble nose. The experimental and theoretical studies of Dumitrescu and Davies and Taylor demonstrated that for a wide range of viscosity and surface tension, the rising velocity of a Taylor bubble in a vertical pipe filled with stagnant liquid $\left(V_{B_{0}}\right)$ can be expressed in term of a constant Froude number $(F r)$ :

$$
F r=V_{B_{0}} / \sqrt{g D_{p}}=0.351 \quad\left(V_{B_{0}}=0.35 \sqrt{g D_{p}}\right),
$$


where $D_{p}$ is diameter of the pipe and the shape of a Taylor bubble considers spherical at the nose. The work of Dumistrescu and Davies and Taylor served as the starting point for the investigation of an elongated bubble velocity in slug flow. Otherwise, experiments by Harmathy (1960), Nicklin et al. or White and Beardmore (1962), Zukoski (1966) and others all showed that $F r=0.35 \pm 0.05$.

Griffith and Wallis and Nicklin et al. showed that, in an upward flowing liquid, the rising velocity of a Taylor bubble clearly must depend on the velocity of the liquid flowing upstream as well as on the rise due to buoyancy, and the Taylor bubble velocity in liquid flowing could be expressed as:

$$
V_{B}=C V_{L}^{\prime}+V_{B_{0}},
$$

where $C$ is an empirical coefficient $(C=1.2$ for $R e>8000)$ and $V_{L}^{\prime}$ is the average liquid velocity ahead of the bubble given by $V_{L}^{\prime}=V_{L}+V_{G}$ and $V_{L}$ and $V_{G}$ are the superficial gas and liquid velocities in the pipe. Thus $V_{B}$ can be expressed as:

$$
V_{B}=1.2\left(V_{L}+V_{G}\right)+0.35 \sqrt{g D_{p}} .
$$

In order to obtain the velocity data, many techniques are used. Shemer and Barnea (1987) used hydrogen bubble technique to study the velocity profiles behind the Taylor bubble in both vertical and horizontal slug flows. Nakoryakov et al. (1989) studied instantaneous velocity fields in a vertical flow using an electrochemical velocity probe. Hassan and Canaan (1991) used PIV (Particle Image Velocimetry) technique to obtain instantaneous velocity field of the particles or bubbles. Mao and Dukler (1991) predicted accurately the value of translation velocity of a single Taylor bubble in vertical tubes by using two pairs of conductance and a double electrochemical probe. Kashinsky and Timkin (1999) used LDA (Laser Doppler Anemometer) for measurement of the local slip velocity of spherical bubbles. Recently Hills and Chety (1999) study an experimental investigation of the rising velocity of Taylor bubbles in an annulus using video images. However, instantaneous rising velocity measurements of a single Taylor bubble in a vertical pipe by using digital image analysis techniques are still scarce and relatively new.

In this paper, a new velocity measurement technique, a non-invasive measurement, using digital image analysis techniques is proposed. The advantage of this technique is that it allows measuring accurately the instantaneous rising velocity of a single Taylor bubble in any desired position along the pipe, and for both stagnant and flowing liquid. Moreover this technique corresponds to both types of flow: full developed and developing slug flows(where the nose of the bubble is distorted and becomes alternately eccentric on one side or another).

\section{Experimental system}

The schematic diagram of the experimental system (Fig. 1) consists of an air and water supply system and a vertical annular transparent pipe (ID: $30 \mathrm{~mm}, 70$ 
diameter long). Water was pumped in a closed loop from the tank to the test section and back to the tank, where bubbles are removed. The flow rate is regulated during each experiment. Air is supplied from a small compressed air. The movement of each Taylor bubble is recorded by a Samsung CCD camera (SAC-410ND) in the test section; a Fujinon D6X8.5C-MPX21 (8.5 to $51 \mathrm{~mm}$ ) motorized lens; a DC motor driver and a PC I/O interface board are also used to control the motorized lens via computer. The output video signals of the CCD Camera are connected to a frame-grabber board (Matrox Meteor-II). These images are digitized and stored directly in the RAM of a Pentium PC-586 (128RAM) and then transferred to a hard disk for image analysis. To obtain the best results, a light source $4 \times 100 w$ was installed in front of camera but behind the pipe. Image data acquisitions are executed automatically by special software (Matrox Imaging Library), which is written in Visual $C^{++}$5.0. A sequence of 100 recorded images of individual bubbles for each experiment is performed. The time interval between two consecutive image frames is $0.03 \mathrm{~s}$, corresponding to $30 \mathrm{frames} / \mathrm{s}$. The image size used in experiments is in a form of an array of $52 \times 320$ picture elements (pixels) of eight bit. Digital image processing program is written in Matlab. A rule was recorded as part of the bubble images and this was used to convert the scale from pixels to centimeters.

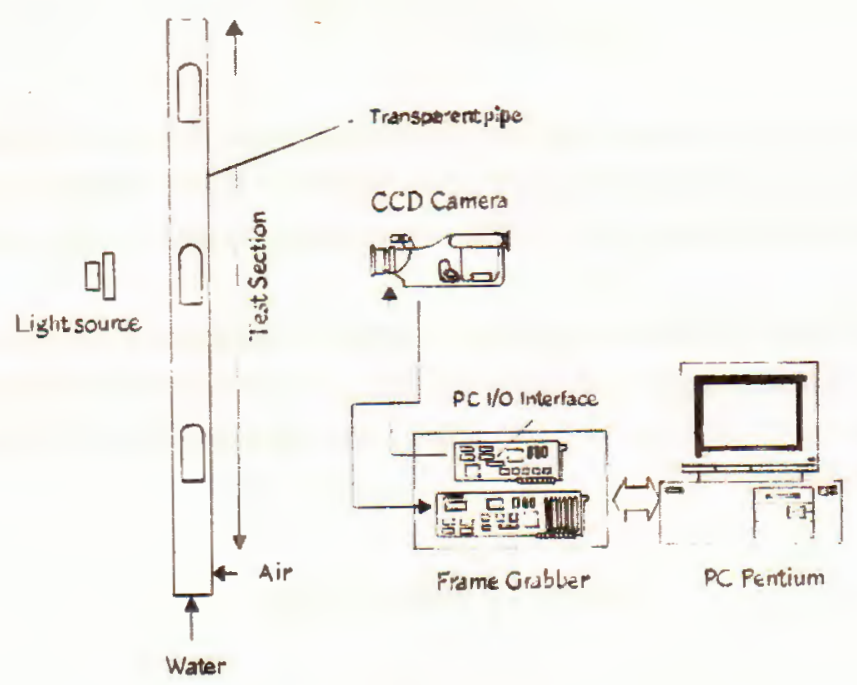

Fig. 1. The schematic diagram of the experimental system

\section{Measurement technique}

\subsection{Image processing}

The previous studies showed that: in fully developed slug flow, all bubbles have smoothly rounded heads or a symmetrical shape with a spherical cup and rise with approximately the same velocity. In developing slug flow, the rise velocity changes 
quite randomly as the shape changes, these changes are irregular from frame to frame. This means that, it's very difficult to describe, to define the position and measuring the instantaneous rise velocity of a Taylor bubble. Therefore, using digital image processing techniques (image filtering, edge detection, thresholding and binary images, etc.) in these cases is best suitable for resolving the above problems. This process was showed in detail by Bui Dinh and Choi $(1999,2000)$, which were correspondent to a random bubble shape).

\subsection{Principle of bubble velocity measurement}

In order to measure the instantaneous rising velocity of a single Taylor bubble; two experimental solutions were used. The first solution, measurements are performed on the bubble nose tips of the two consecutive image frames. The second solution was made by measuring the successive displacement between the two positions of the center of the bubble in two corresponding successive image frames with the known temporal separation. According to the first solution, an algorithm was developed to allow the computer to record the coordinates of any desired point in the image; in this case, it's the tip of the bubble nose. These tips are identified by the movement of a user-controlled cursor, which was controlled manually. Thus the instantaneous rising velocity of a single Taylor bubble $\left(V_{b}\right)$ can be expressed as:

$$
V_{b}=\frac{\sqrt{\Delta x^{2}+\Delta y^{2}}}{\Delta t}
$$

where $\Delta x$ is horizontal $(x)$ displacement of the bubble nose tip between two consecutive image frames, $\Delta y$ - vertical $(y)$ displacement of the bubble nose tip between two consecutive image frames, $\Delta t$ - Time separation between two consecutive image frames.

The second solution is based on binary image-processing techniques of Berthold (1986), in which a binary image is defined by a characteristics function $b(x, y)$ that takes on the values zero or one. In our case, we assume that if the area of a single Taylor bubble is defined:

$$
A_{b}=\iint_{I} b(x, y) d x d y
$$

where this integration is over the whole image $I$.

Then, the position of the center of this bubble $(\bar{x}, \bar{y})$ can be found as follows:

$$
\begin{gathered}
\bar{x} A_{b}=\iint_{I} x b(x, y) d x d y=\int x v(x) d x \\
\bar{y} A_{b}=\iint_{I} y b(x, y) d x d y=\int y h(y) d y,
\end{gathered}
$$


where $v(x)$ and $h(y)$ are the vertical and horizontal projections of the bubble on the $x$-axis and $y$-axis. In fact, the position of the center of any Taylor bubble in the image can be determined as follows: From binary image of any desired Taylor bubble (Fig. 2 presents an example of this determination), to choose two points to click. These points (identified by the movement of a user-controlled cursor, which was controlled manually) locate on the two opposite heads of the diagonal of an imaginary rectangle, which just contains this bubble. An algorithm was developed to allow the computer to record the coordinates of these points in the image and then the position of the center of the bubble will be determined by using the equation (3.3) and (3.4). Finally, applying equation (3.1), the instantaneous rising velocity of a single Taylor bubble will be determined by measuring the displacement between the two positions of the center of the bubble in two corresponding successive image frames with the known temporal separation $(\Delta t)$. However, where $\Delta x$ is the horizontal $(x)$ displacement of the center of the bubble between two consecutive image frames and $\Delta y$ is the vertical (y) displacement of the center of the bubble between two consecutive image frames.

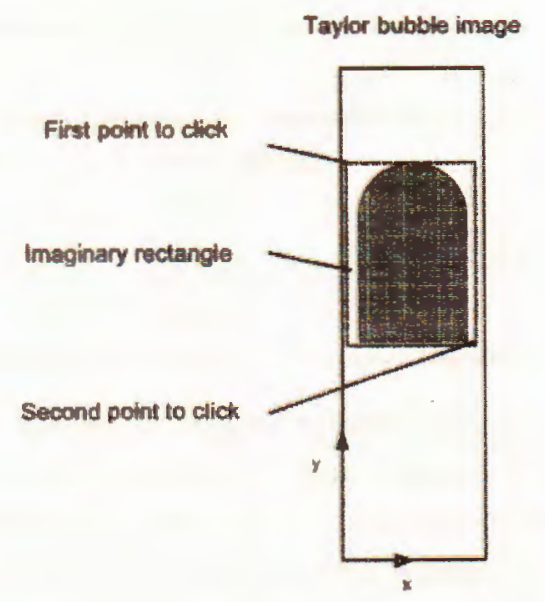

Fig. 2

\section{Experimental results}

Experiments are carried out in stagnant and upward flowing liquid (with average flow velocity $V_{L}^{\prime}$ is about $0.15 \mathrm{~m} / \mathrm{s}$ ) and for both types of full developed and developing slug flow. Moreover, in order to obtain the precise results, measurements are performed at five consecutive image frames of the same Taylor bubble. Finally, due to the large number of measurements, only a few of them will be presented here.

In full developed slug flow, due to the distance between any two consecutive Taylor bubbles is large enough, so that these bubbles aren't influenced by wake of the leading one. Figure 3 shows an example of five consecutive image frames of a rising Taylor bubble, including the original images and their binary images (Figure 4), bubble contours (Figure 5), which were obtained by using image-processing techniques. Figure 6 represents five consecutive bubble nose tip positions, which are used to calculate the instantaneous velocity data. By using the first solution proposed (based on the bubble nose tip displacement), the experimental results are showed that the bubble rises with a uniform velocity (the difference is negligible). The Table 1 below shows the instantaneous velocities obtained $\left(V_{b_{0}}\right)$ between two image frames and their corresponding Froude number, in stagnant liquid. 
Table 1

\begin{tabular}{|c|c|c|c|c|}
\hline & Image No. 1-2 & Image No. 2-3 & Image No. 3-4 & Image No. 4-5 \\
\hline$V_{b_{0}}(\mathrm{~m} / \mathrm{s})$ & 0.1929 & 0.1940 & 0.1904 & 0.1921 \\
\hline $\begin{array}{c}\text { Froude } \\
\text { Number } \\
\quad(F r)\end{array}$ & 0.3558 & 0.3578 & 0.3513 & 0.3543 \\
\hline \multicolumn{5}{|c|}{ Table 2} \\
\hline & Image No. 1-2 & Image No. 2-3 & Image No. 3-4 & Image No. 4-5 \\
\hline$V_{b}(\mathrm{~m} / \mathrm{s})$ & 0.376 & 0.371 & 0.380 & 0.375 \\
\hline$C$ & 1.24 & 1.22 & 1.26 & 1.23 \\
\hline
\end{tabular}

In developing slug flow, as all bubbles are influenced by flow in the wake of their predecessors and the nose of the bubble is distorted and becomes not spherical in shape, and so in this case, the second solution was used. An another example of five consecutive image frames of a pair of Taylor bubbles which are rising in developing slug flow with the liquid flow is about $0.15 \mathrm{~m} / \mathrm{s}$. The original, binary images and bubble contours of these bubble are showed in the figures 7, 8 and 9 . Figure 10 shows five consecutive positions of the center of the bubble. These positions are used to calculate the instantaneous velocity data. By using the second solution (based on the displacement of the center of the bubble), the measured instantaneous velocities $\left(V_{b}\right)$ between each of two image frames of specified Taylor bubble are showed in Table 2. Where $C$ is an empirical coefficient (which is calculated from the measured values of $V_{b}$ ), the values of the coefficient $C$ are slightly change while using the same liquid velocity. The calculations were based on the conversion scale, which was found to be 18 pixels $/ \mathrm{cm}$. The errors associated with these experiments are about $2 \%$, involving the process of bubble center determination, random errors in the image acquisition process, the fluctuation and the change irregularly of the bubble size, shape, etc.

\section{Conclusions}

In this study a new method available for instantaneous velocity measurements of a single Taylor bubble rising in vertical upward two-phase flow regimes is proposed. Digital image processing algorithms have been developed to obtain the coordinates of any desired point on the image. These coordinate data are used to calculate the velocity one. The experimental results show that the instantaneous rising velocity of a single Taylor bubble can be measured quite accurately by using digital image analysis techniques. In particular, for developing slug flow, where the size, shape 
and the rise velocity of each bubble change quite randomly. The results measured also show that the Froude numbers $(\mathrm{Fr})$ and the empirical coefficient $\mathrm{C}$ are in good agreement with the previous experimental result literatures. However this technique is additional, and has been developed to demonstrate the applicability of a noninvasive measurement of a single Taylor bubble velocity using digital image processing analysis techniques.

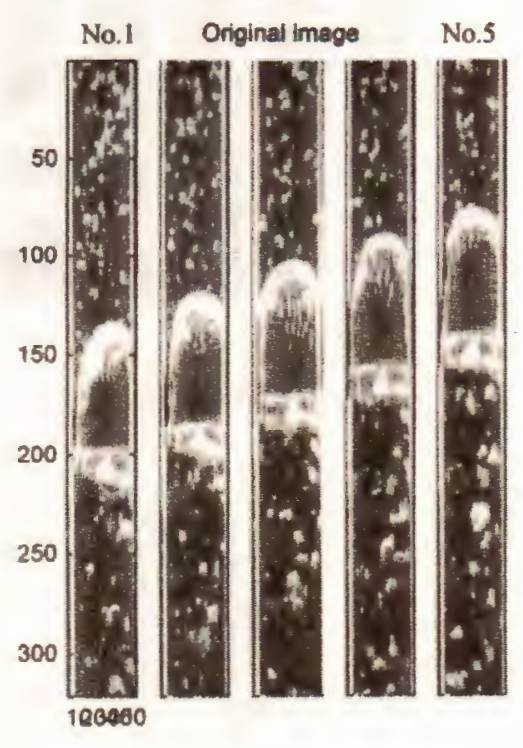

Fig. 3. Original images

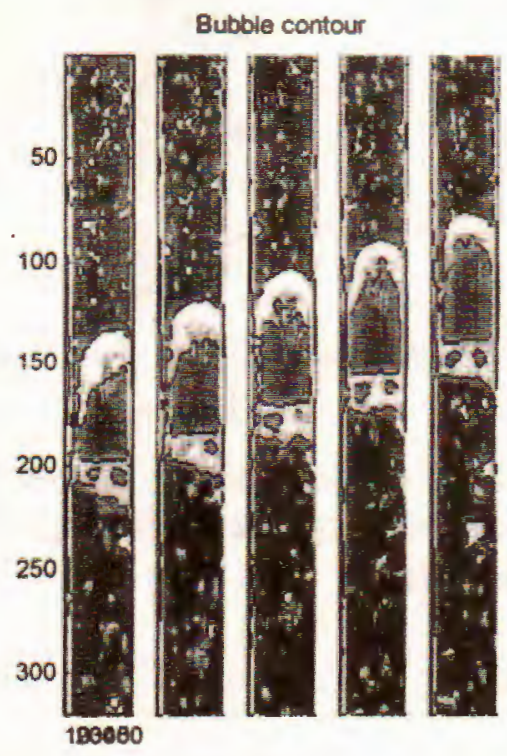

Fig. 5. Bubble contours

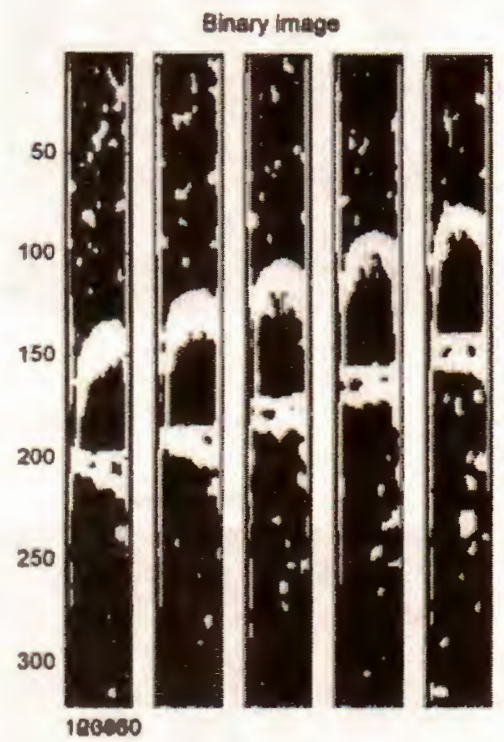

Fig. 4. Binary images

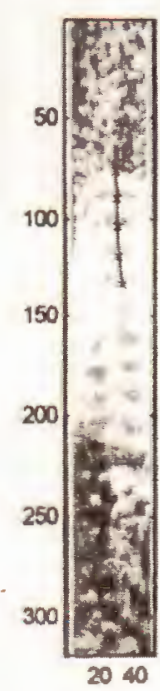

Fig. 6. Bubble nose tip displacement 


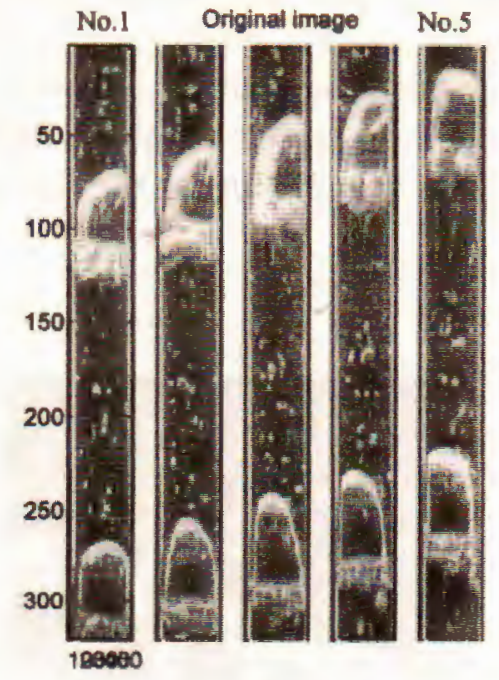

Fig. 7. Original images

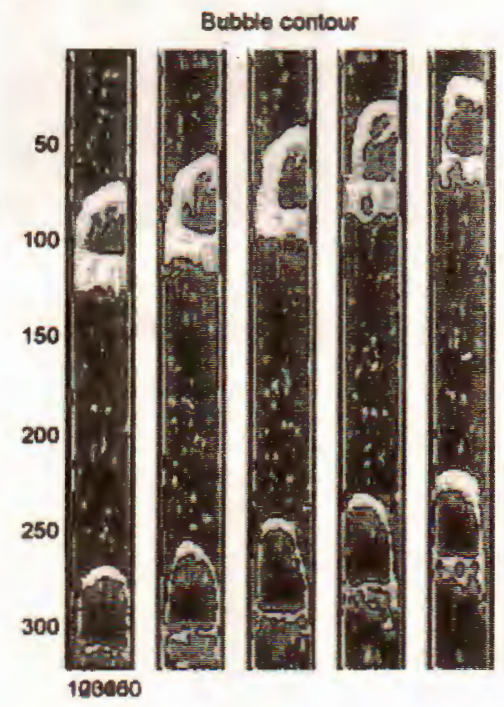

Fig. 9. Bubble contours

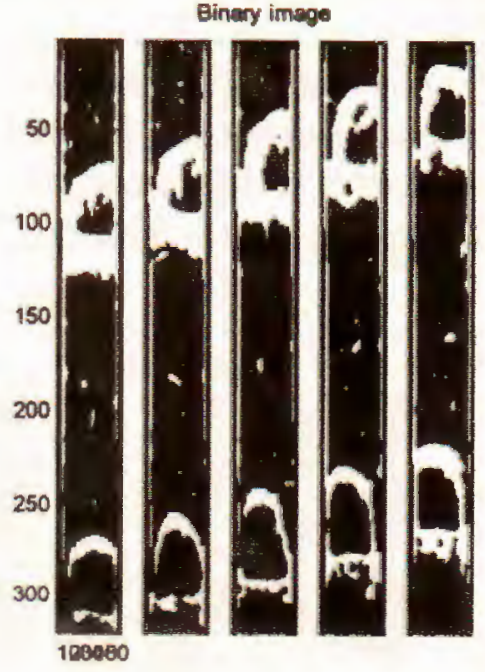

Fig. 8. Binary images

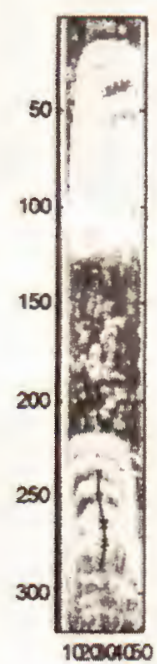

Fig. 10. Displacement of the center of the bubble

This work was supported by the Council for Natural Science of Viet Nam. The author also thank all colleagues at Kwangju Institute of Science \& Technology KJIST - Korea) for their support in the first part of this work.

\section{REFERENCES}

1. Barnea D., Brauner N. (1985). Hold-up of the liquid slug in two-phase intermittent flow. Int. J. Multiphase flow 11, 43-49. 
2. Barnea D., Taiteil Y. (1993). A Model for slug length distribution in gas liquid slug flow. Int. J. Multiphase flow 19, 829-838.

3. Berthold K. P. H. (1986) Robot vision, 47-61, MIT press, McGraw-Hill.

4. Bui Dinh T. and Choi T. S. (1999). Application of image processing techniques in two-phase flow; Mech. Res. Com. 26 (4), 463-468.

5. Bui Dinh T. and Choi T. S. (2000). Bubble velocity measurements using binary image processing techniques, Proc. SPIE 45th USA, Vol. 4115-64.

6. Bui Dinh T. and Choi T. S. (2000). Instantaneous bubble velocity measurements using digital image analysis, Optical Engineering (Accepted)

7. Davies R. M., Taylor G. I. (1949). The mechanics of large bubbles rising through extended liquid and through liquid in tubes. Proc. R. Soc. Lond. Ser. A 200, 375-390.

8. Dumitrescu D. T. (1943). Ref. from Moissi, R. \& Griffith, P., J. Heat Transfer 1962. 29-39.

9. Griffith P. and Wallis G. B. (1961). Two-phase slug flow. J. Heat Transfer 83, 307-320.

10. Hassan Y. A.and Canaan R. E. (1991). Full-field bubbly flow velocity measurements using a multiframe particle tracking technique. Exp. Fluid 12, 49-60.

11. Harmathy T. Z. (1960). Velocity of large drop and bubbles in media of infinite or restricted extent. AIChE J. 6, 281-288.

12. Hills J. H. and Chety P. (1998). The rising velocity of Taylor bubbles in an annulus. Trans. IChemE, 76, Part A, 723-727.

13. Kashinsky O. N., Timkin L. S. (1999). Slip velocity measurements in an upward bubbly flow by combined LDA and electrodiffusional techniques. Exp. Fluid, 26, 305-314.

14. Moissis R., Griffith P. (1962). Entrance effects in a two-phase slug flow. J. Heat Transfer. 29-39.

15. Mao Z. S. and Duckler A. E. (1990). The motion of Taylor bubble in vertical tubes-I A Numerical simulation for shape and rise velocity of Taylor bubbles and flowing liquid. J. Computational Phys., 91, 132-160.

16. Mao Z. S. and Duckler A. E. (1991). The motion of Taylor bubbles in vertical tubes-II. Experimental data and simulations for laminar and turbulent flow. Chem. Eng. Sci. 46(8), 2055-2064. 
17. Nicklin D. J. (1962). Two-phase bubble flow. Chem. Eng.Sci. 17, 693-702.

18. Nicklin D. J., Wilkes J. O., Davidson J. F. (1962). Two-phase flow in vertical tubes. Trans.IChemE. 40, 61-68.

19. Nakoryakov V. E. et al. (1989). Study of local hydrodynamics characteristics of upward slug flow. Exp. Fluid 7, 560-566.

20. Shemer L., Barnea D. (1987). Visualization of instantaneous velocity profiles in gas-liquid slug flow. Physicochem. Hydrody. 8, 243-253.

21. White E. T. and Beardmore R. H. (1962). The velocity of rise of single cylindrical air bubbles through liquids contained in vertical tubes. Chem. Eng. Sci. 17, 351-361.

22. Zukoshi E. E. (1966). Influence of viscosity, surface tension, and inclination angle on motion of long bubbles in closed tubes. J. Fluid Mech. 25, 821-837

Received February 13, 2001

ĐO VẬN TỐC BỌT TAYLOR TRONG DÒNG 2 PHA KHÍ/NƯớC CHUYỂN ĐỘNG THẰNG ĐÚNG

Bài báo này đề xuất một phương pháp đo vận tốc tức thời của bọt Taylor đang chuyển động đi lên trong dòng 2 pha khí/nước. Phương pháp này dược dựa trên kỹ thuật xử lý một chuỗi liên tiếp những ảnh đã được số hóa và kỹ thuật xử lý ảnh nhị phân.

Vận tốc tức thời của những bọt này là một hàm của khoảng cách giữa 2 vị trí (ảnh) liên tiếp của đỉnh bọt (hoặc tâm bọt) với thời gian đã được xác định . Phương pháp này cho phép nghiên cứu, do đạc rất chính xác ở cả hai kiểu chế độ của dòng cháy: đã và dang phát triển dòng Slug (full developed and deceloping slug flows). Một phần quan trọng của công việc này (dựng thiết bị thí nghiệm, ghi và số hóa anhh) đã được thực hiện tại Viện Khoa Học Công Nghệ Kwangju- Hàn Quốc.

Viện Cơ học

264 Doican, Badinh, Hanoi

E-mail: bdtri@im01.ac.vn 